\title{
The "top 50": a perspective on the BMF drawn from the Science Citation Index
}

\author{
Bernard Dixon
}

The emergence of modern epidemiology, the increasingly detailed study of drug side effects and metabolism, and the considerable individual influence of Sir Richard Doll are three themes to emerge from my study of the 50 British Medical Fournal papers that were cited more frequently than any others during 1945-89. The study also discloses some surprises in the list of individual papers that have been heavily cited and whose impact thus reflects their unusual influence on other authors. In addition, the analysis provides striking confirmation of the BMF's strength in clinically oriented publications, as shown recently by Shaw in a paper that shows that $62 \%$ of the journal's most highly cited papers cover clinical research, in contrast with $55 \%$ of those of the Lancet. ${ }^{1}$

Conceived by Eugene Garfield and published by his Institute for Scientific Information, which is based in Philadelphia, the Science Citation Index is primarily a tool for retrieving information. An author can use it to find out, for example, how many times and where a paper has been included as a reference in other authors' publications. But, as Garfield pointed out in 1955, citation counts also mirror an author's impact in the scholarly community. While a paper describing research with Nobel prize potential is soon attracting many citations a trivial or insignificant paper is usually ignored.

Garfield has repeatedly pointed out that citation ratings must be interpreted carefully and that they should not be used simplistically to compare the quality of work by particular researchers, departments, or institutions. Despite these warnings administrators and funding bodies have become increasingly attached to citation analysis-especially during times of financial stringency, when a quantitative measure seems to offer concrete guidance in allocating scarce funds.

There are, of course, real caveats that need to be borne in mind in using "scientometric" data. Self citation, for example, can be used to boost an author's citation rating. Secondly, a paper that is demonstrably erroneous may be cited for that very reason. But such aberrations do not seem to cause important problems when the upper strata of heavily cited papers are being considered. Likewise, some critics of citation analysis seem to believe that the development of techniques is an intellectually inferior pursuit to the evolution of new ideas and argue that citation counts give disproportionate emphasis to papers that differ little from popular new cookery recipes. In fact, investigational methods do have crucial roles in the advancement of science-another point illustrated by the study reported here.

The box lists the "top 50 papers" that have been published in the $B M F$ in order of their citation counts as derived from the Science Citation Index for 1945-89. Also given is the average number of citations received by each paper a year. Clearly, both sets of figures need to be interpreted in relation to the amount of time that has elapsed since publication, during which other authors could have cited a particular paper.

Middlesex HA4 6AW Bernard Dixon, PHD, former editor of "New Scientist"

BrMed f 1990;301:747-51

\section{Epidemiology: the major theme}

Thirteen of the papers concern epidemiology, and 14 cover various aspects of drug reactions and metabolism, but seven papers fall into both of these non-exclusive categories. Five were on mortality

\section{0s}

- 1940: Howard Florey, Ernst Chain, and others begin clinical testing of penicillin, which had been discovered 11 years earlier by Alexander Fleming

- 1949: Linus Pauling describes the molecular basis of sickle cell anaemia

- 1949: Clinical introduction of "compound E" (cortisone) by P S Hench and others

from thromboembolism and cardiovascular causes in relation to the use of oral contraceptives. These were the 1970 and 1968 reports (with 464 and 409 citations respectively) for the Committee on Safety of Drugs by William Inman and his colleagues; the 1968 and 1969 papers ( 354 and 357 citations respectively) by Martin Vessey (a coauthor of the Inman papers) and Richard Doll; and the 1975 paper (340 citations) by J I Mann and colleagues, who also included Vessey and Doll.

The other two papers that fall into both categories, with 308 and 298 citations, examined the rise in mortality from asthma that occurred in England and Wales during the 1960s and questioned (inconclusively) whether new methods of treatment such as corticosteroids and aerosols containing sympathomimetics were to blame. They were written by $\mathrm{F} \mathrm{E}$ Speizer and colleagues-including Richard Doll.

Among the remaining epidemiological papers the top score (577 citations) was logged by Alice Stewart and her colleagues in the School of Social Medicine at Oxford University for their survey in 1958 of childhood malignancies. As she explained many years later, this report would never have appeared had the group not persisted with its plans after the Medical Research Council refused to fund the project. ${ }^{3}$ Stewart and her coworkers were puzzled by an early peak of deaths consisting solely of children with lymphatic disease that they had noticed in the postwar increase in the incidence of leukaemia. Mindful of the possible role of $x$ rays during pregnancy, they wanted to organise nationwide interviews with mothers of children with leukaemia and control subjects. Rejected by the Medical Research Council, the Oxford workers found the train fares to do the work themselves and in due course published the paper that is now third in the BMF's roll of honour. Although this study did not provide immediate answers, it prompted two important discoveries - that all childhood cancers have fetal origins and that cancers of the immune system can affect reactions to other diseases before they are themselves recognisable clinically.

The next most heavily cited epidemiological papers, scoring 544 and 444 respectively, are the classics in which Doll and Peto (1976) and Doll and Sir Austin Bradford Hill (1964) presented the findings of 20 years and 10 years of observations on smoking and mortality among doctors, after a questionnaire was sent out by the BMA in October 1951. These extended the conclusions of Doll and Bradford Hill in their 1956 paper (312 citations) that mortality was higher in smokers than in non-smokers, in heavy compared with light smokers, in those who smoked cigarettes rather than those who smoked a pipe, and in those who 
continued with their habit compared with those who abstained.

In one of the remaining epidemiological papers Ian Aird and collaborators in London showed that blood group A was commoner and group D rarer in patients with stomach cancer than in the general population ( 350 citations). This and subsequent studies did not, as the authors hoped, explain geographical differences in the prevalence of the condition. They did, however, lead to our more precise understanding of disease propensities in relation to particular histocompatibility antigens in body tissues.

The final epidemiological study, with 316 citations, was by Anthony Allison at Oxford University. Building on several earlier papers by E A Beet and P Brain in the East African Medical Fournal and the South African Medical Fournal a few years earlier, he showed that the sickle cell trait protected carriers against malarial infection. This balance of advantage and disadvantage helped to explain why the sickle cell gene had been preserved in certain communities rather than being eliminated by natural selection.

\section{Drug metabolism and reactions}

Most highly cited of the remaining seven papers on physiological responses to drugs was that published in 1960 (370 citations) in which David A Price Evans and colleagues at Johns Hopkins University, Baltimore, investigated large person to person variations in the metabolism of isoniazid, which had come into general use against tuberculosis during the 1950s. They presented evidence for a genetic polymorphism, with people being slow inactivators or rapid inactivators of the drug (the slow inactivator character is recessive). Nine years later Evans, then at Liverpool University, coauthored a paper with B Alexanderson and F Sjoqvist at the Karolinska Institute in Stockholm (304 citations) that showed that most of the variability in plasma concentrations of the tricyclic antidepressant nortriptyline was also genetically determined.

Biochemical abnormalities suggestive of osteomalacia observed in epileptic patients consuming a diet containing adequate levels of vitamin D were the starting point for studies reported in 1970 by researchers at St Bartholomew's Hospital Medical School and University College Hospital Medical School, London. C E Dent and colleagues (354 citations) and Alan Richens and D J F Rowe (334 citations) suggested for the first time that anticonvulsants such as phenytoin could induce the formation of liver enzymes capable of breaking down vitamin D.

In her 1969 paper (291 citations) Natalie Hurwitz of Queen's University, Belfast, reported that there were significantly more adverse drug reactions in elderly patients than in young patients and more in women than in men. Two years later Kevin O'Malley and colleagues at Dundee University (350 citations) offered a possible partial explanation on the basis of studies on

Scanning electron micrograph of a colony of "Campylobacter jejuni" (magnification $\times 2900$ ) the metabolism of antipyrene and phenylbutazone in geriatric inpatients. They found mean plasma half lives $45 \%$ and $29 \%$ respectively greater than those in young subjects, as well as longer half lives in women compared with men. In their 1971 paper (449 citations) Marie Asberg and her colleagues at the Karolinska Institute suggested that a too high or too low plasma concentration of nortriptyline could explain why the drug sometimes failed to deal with depressive symptoms.

\section{Novel treatments}

The pharmacologically oriented papers with the highest ratings - in fourth place overall with 546 citations and eighth place with 450 citations - are those in which Brian Prichard and Peter Gillam, working at University College Hospital Medical School, presented results of the first substantial trials of the 6 blocker propranolol as a successor to pronethalol (whose use had been discontinued) in the treatment of hypertension. Another highly placed paper, in 12th place with 419 citations, was that in which Sidney Truelove and Leslie Witts in Oxford (with the cooperation of Richard Doll) showed the value of cortisone in patients with ulcerative colitis (though with the warning that penicillin and sulphonamides should be used to prevent pyogenic complications).

A particular curiosity is the 1972 report by Michael Besser and colleagues (339 citations). Based on collaborative research between St Bartholomew's Hospital Medical School and the National Institute for Research in Dairying, Reading, this showed that bromocriptine, an ergot alkaloid derivative, could be used to treat galactorrhoea. As Besser later pointed out, ${ }^{4}$ this breakthrough marked a highly unusual coincidence-the discovery of a new human hormone (prolactin) simultaneously with the introduction of a treatment for its disturbed secretion. A follow up paper from the same group at St Bartholomew's two years later by Michael Thorner and colleagues has already attracted 430 citations - probably because bromocriptine is becoming the treatment of choice for large prolactin secreting tumours.

Perhaps the biggest surprise, however, is the 1974 paper by Peter Elwood and collaborators at the Medical Research Council Epidemiology Unit in Cardiff ( 353 citations) on the possible use of aspirin to prevent myocardial infarction; the study was performed after observations that aspirin could prolong platelet aggregation time. Elwood's group reported reductions in total mortality but said that these were statistically inconclusive and that further trials were urgently required. Fifteen years later the authors of a major American study have claimed a definite reduction in the risk of myocardial infarction in subjects taking aspirin but stated that the effect on cardiovascular morbidity remains inconclusive.

Top of the entire $B M \mathcal{F}$ listing, with a score of 820 citations, is the 1953 paper in which (now Sir) Andrew Watt Kay, working at the Western Infirmary, Glasgow, described the effect of increasing doses of histamine on the gastric secretion of hydrochloric acid in normal subjects and in patients with duodenal ulcer. On the basis of these observations he developed a new and extremely consistent routine test. Imposing a uniform and maximum stimulus on the acid secreting cells, it supplanted the somewhat arbitrary and unreliable assay that was used until that time.

Martin Skirrow of the Public Health Laboratory at Worcester Royal Infirmary authored the 1977 paper that lies in second place with 808 citations and has scored many more citations each year $(67 \cdot 3)$ than any other paper. When Skirrow first found campylobacter in a baby with fever of undetermined origin he was 


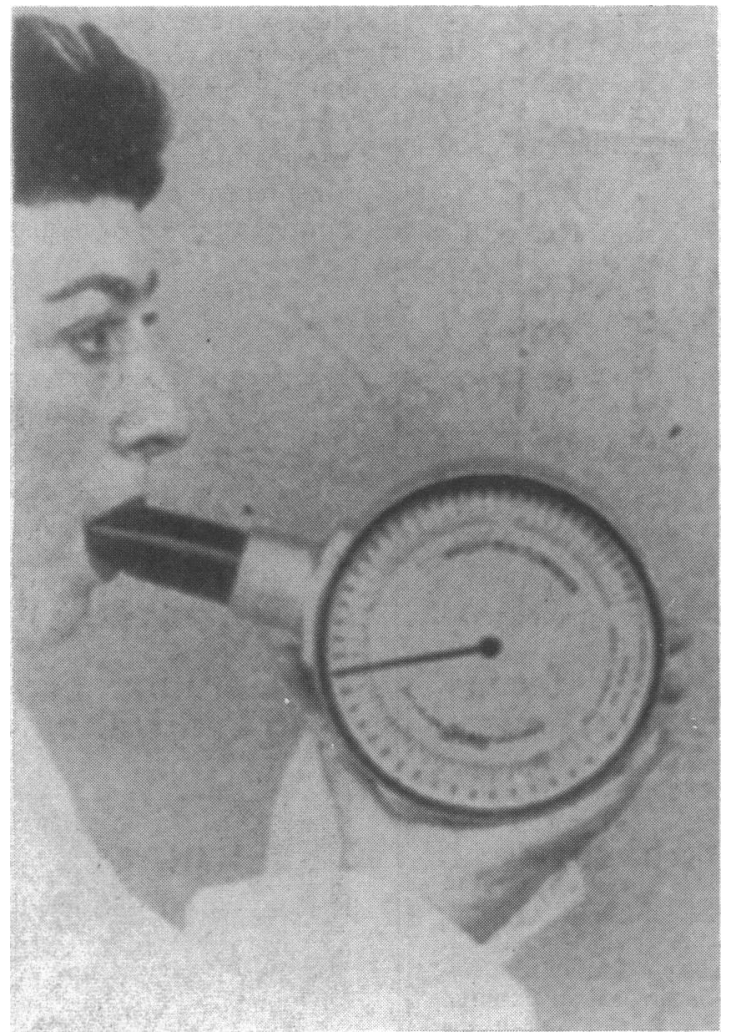

conscious that it was known almost exclusively as a cause of abortion in livestock. So he was sceptical when a literature search led him to Belgian reports of campylobacters in $5 \%$ of children with diarrhoea. But a novel culture method then showed campylobacters in as many as $7 \cdot 1 \%$ of his patients with acute diarrhoea, including adults. "It seems that campylobacters ( $C$ jejuni and $C$ coli) are an important addition to the growing list of known enteric pathogens," Skirrow wrote. "Indeed, if the samples received in this laboratory are typical of those in the rest of the country, they are the commonest identifiable cause of infectious diarrhoea."

That prophecy has been amply justified not only in Britain but throughout the world. In just one decade the reputation of $C$ jejuni has been transformed from that of an obscure veterinary pathogen into that of a major contributor to human lavatorial misery the world over. The key to the emergence of this knowledge was the selective culture technique applied by Skirrow to suppress the normal faecal flora and permit campylobacters to grow.

A third technique of lasting importance, described by $B$ Wright and Colin McKerrow in their paper, placed 19th (368 citations), is the measurement of maximum forced expiratory flow rate. Published in 1959, the paper described the introduction of the peak flow meter, developed at the Medical Research Council's Pneumoconiosis Research Unit in the Welsh coal fields. Commenting on the work over 20 years later, ${ }^{6}$ Wright recalled that physiologists were "a bit sniffy" about the device at first (they argued that the correct way to measure flow was by volume and time). Nevertheless, he wrote, "my reward is knowing that I have made a substantial and perhaps permanent contribution to clinical medicine." A recent report by Kevin Jones and Mark Mullee suggests that Wright was right.

Other notable methods are recorded in the papers by Allan Jacobs and coworkers (378 citations) on the measurement of ferritin concentrations associated with iron deficiency and overload; by Anthony Halliday and colleagues ( 364 citations) on the diagnosis of multiple sclerosis; and by Douglas Coltart and D G Shand ( 324 citations) on the determination of plasma concentrations of propranolol associated with reductions in endogenous and exogenous cardiac $\beta$ adrenergic stimulation. In the surgical domain the preliminary communication by New Zealander (now Sir) William Liley in 1963 (308 citations) was his first report of successful intrauterine blood transfusion to save the life of a severely anaemic $\mathrm{Rh}$ positive fetus. In their 1972 paper (308 citations) Sir Hedley Atkins and his colleagues recorded the superiority of radical mastectomy over wide excision (extended tylectomy) in patients with stage 2 breast cancer.

\section{Other highlights}

Aside from these principal categories, the BMF's top 50 includes several papers which, in one way or another, reflect the paradigms of their time. Tumour specific antibodies in patients with melanoma were the subject of the 1969 paper (449 citations) by M G Lewis and colleagues (including Gordon Hamilton Fairley, who was killed by the IRA in 1975) at four London cancer institutions and collaborating centres in Bulgaria and Australia. The 1972 paper by Donald Laurence and coworkers at the same four institutions (370 citations) explored the possible value of carcinoembryonic antigen in detecting residual tumour cells after therapeutic intervention. Peter Alexander's name was on both papers.

Another sign of the times is the 1971 paper (288 citations) in which Neil Painter and Denis Burkitt, under the journal's "For Debate" rubric, used geographical, historical, and physiological evidence to argue that diverticulosis coli was a preventable disease caused by the consumption of refined carbohydrates. Less contentious was the 1978 report by D J A Jenkins and coworkers (384 citations) on the use of fibre supplements to decrease postprandial hyperglycaemia in diabetic patients.

\section{Patterns of citation}

Some of the papers in this listing show the typical pattern in which citations build up over a period of years and then decay to virtually nothing. Ian Aird's paper (350 citations), for example, attracted 10-15 citations each year during the 1950 s and 1960 s but now receives only three or four each year. A few primordial but contentious papers have continued to be well cited over a considerable period. For example, that by Stewart and colleagues (577 citations) has received at least eight citations each year for the past 20 years, after its peak of 48 citations in 1966. Most striking of all is Ernest Walton's 1958 paper on Wegener's granulomatosis, which now totals 306 citations after receiving 11 or more citations in all but one of the past 14 years-presumably because it is a definitive description of the condition.

Although published 34 years ago, the paper by Truelove and Witts on ulcerative colitis ( 419 citations) has been cited increasingly in recent years, from a handful of citations each year in the late 1960s and early 1970 s to $20,30,32$, and 33 citations in the past four years respectively. Equally significant is the record for the 1941 paper in which Eric Bywaters and D Beall described a hitherto unrecognised syndrome in air raid casualties (313 citations). They observed the syndrome in patients who were buried for several hours with pressure on a limb, went into shock some time later, and then, despite fluid replacement, developed renal damage and died within a week. Citations of this paper fell from an initial 10-20 each year to very low levels, and it did not reach even the top $100 B M \mathcal{F}$ papers when 


\section{The BMF's top 50}

The 50 most cited British Medical fournal papers as recorded in the 1945-89 Science Citation Index in order of citation score. Figures in parentheses are the mean numbers of citations a year

$820(22 \cdot 8)$ A W Kay. 1953;ii:77-80. Effect of large doses of histamine on gastric secretion of $\mathrm{HCl}$. An augmented histamine test.

808 (67·3) M B Skirrow. 1977;ii:9-11. Campylobacter enteritis: a "new" disease.

577 (18.6) A Stewart, J Webb, and D Hewitt. 1958;i:1495-508. A survey of childhood malignancies.

546 (27.3) B N C Prichard and P M S Gillam. 1969;i:7-16. Treatment of hypertension with propranolol.

$544(41 \cdot 8)$ R Doll and R.Peto. 1976;ii:1525-36. Mortality in relation to smoking: 20 years' observations on male British doctors.

500 (45.5) E K Perry, B E Tomlinson, G Blessed, K Bergmann, P H Gibson, and R H Perry. 1978;ii:1457-9. Correlation of cholinergic abnormalities with senile plaques and mental test scores in senile dementia.

464 (24.4) W H W Inman, M P Vessey, B Westerholm, and A Engelund. 1970;ii:

203-9. Thromboembolic diseases and the steroidal content of oral contraceptives: a report to the Committee on Safety of Drugs.

$450(18 \cdot 0)$ B N C Prichard and P M S Gillam. 1964;ii:725-7. Use of propranolol (Inderal) in treatment of hypertension.

449 (27-7) M Asberg, B Cronholm, F Sioqvist, and D Tuck. 1971;iii:331-4. Relationship between plasma level and therapeutic effect of nortriptyline.

449 (25.0) M G Lewis, R L Ikonopisov, R C Nairn, T M Phillips, G Hamilton Fairley, D C Bodenham, and P Alexander. 1969;iii:547-52. Tumour-specific antibodies in human malignant melanoma and their relationship to the extent of the disease.

$444(17 \cdot 8)$ R Doll and A Bradford Hill. 1964;i:1399-410. Mortality in relation to smoking: ten years' observations of British doctors.

430 (28.7) M O Thorner, A S McNeilly, C Hagin, and G M Besser. 1974;ii:419-22. Long-term treatment of galactorrhoea and hypogonadism with bromocriptine.

$419(12 \cdot 3)$ S C Truelove and L J Witts. 1955;ii: 1041-8. Cortisone in ulcerative colitis. 409 (19.5) W H W Inman and M P Vessey. 1968;ii:193-9. Investigation of deaths from pulmonary, coronary, and cerebral thrombosis and embolism in women of childbearing age.

384 (34.9) D J A Jenkins, T M S Wolever, A R Leeds, M A Gassull, P Haisman, J Dilawari, D V Goff, G L Metz, and K G M M Alberti. 1978;i:1392-4. Dietary fibres, fibre analogues, and glucose tolerance: importance of viscosity.

380 (22-4) J J Bullen, H J Rogers, and L Leigh. 1972;i:69-75. Iron-binding proteins in milk and resistance to $E$ scherichia coli infection in infants.

378 (22.2) A Jacobs, F Miller, M Worwood, M R Beamish, and C A Wardrop. 1972;iv:206-8. Ferritin in the serum of normal subjects and patients with iron deficiency and iron overload.

375 (41.7) T J Crow. 1980;280:66-8. Molecular pathology of schizophrenia: more than one disease process?

370 (21.8) D A P Evans, K A Manley, and V A McKusick. 1960;ii:485-91. Genetic control of isoniazid metabolism in man.

370 (21.8) D R J Laurence, U Stevens, R Bettelheim, D Darcy, C Leese, C Turberville, P Alexander, E W Jones, and A M Neville. 1972;iii:605-9. Role of plasma carcinoembryonic antigen in diagnosis of gastrointestinal, mammary and bronchial carcinoma.

$368(12 \cdot 3)$ B M Wright and C B McKerrow. 1959;ii:1041-7. Maximum forced expiratory flow rate as a measure of ventilatory capacity.

364 (22.8) A M Halliday, W I McDonald, and J Mushin. 1973;iv:661-4. Visual evoked response in diagnosis of multiple sclerosis.

357 (18.8) M P Vessey and R Doll. 1969;ii:651-7. Investigation of relation between use of oral contraceptives and thromboembolic disease. A further report.

354 (18.6) C E Dent, A Richens, D J F Rowe, and T C B Stamp. 1970;iv:69-72. Osteomalacia with long-term anticonvulsant therapy in epilepsy.

354 (16.9) M P Vessey and R Doll. 1968;ii:199-205. Investigation of relation between use of oral contraceptives and thromboembolic disease.

353 (22.5) P C Ellwood, A L Cochrane, M L Burr, P M Sweetnam, G Williams, E Welsby, S J Hughes, and R Renton. 1974;i:436-40. A randomized controlled trial of acetyl salicylic acid in the secondary prevention of mortality from myocardial infarction

$350(10 \cdot 0)$ I Aird, H H Bentall, and J A Fraser Roberts. 1953;i:779-801. A relationship between cancer of stomach and the $\mathrm{ABO}$ blood groups.

350 (19-4) K O'Malley, J Crooks, E Duke, and I H Stevenson. 1971;iii:607-9. Effect of age and sex on human drug metabolism.

$340(24 \cdot 3)$ J I Mann, M P Vessey, N Thorogood, and R Doll. 1975;ii:241-5. Myocardial infarction in young women with special reference to oral contraceptive practice.

339 (19.9) G M Besser, L Parke, C R W Edwards, I A Forsyth, and A S McNeilly. 1972;iii:669-72. Galactorrhoea: successful treatment with reduction of plasma prolactin levels by brom-ergocryptine.

334 (17.6) A Richens and D J F Rowe. 1970;iv:73-6. Disturbance of calcium metabolism by anticonvulsant drugs.

325 (12.0) K B Taylor, I M Roitt, D Doniach, K G Couchman, and C Shapland. 1962;ii: 1347-52. Autoimmune phenomena in pernicious anaemia: gastric antibodies.

$324(17 \cdot 0)$ D J Coltart and D G Shand. 1970;iii:731-4. Plasma propranolol levels in the quantitative assessment of beta-adrenergic blockade in man

$316(9 \cdot 0)$ A C Allison. 1954;i:290-4. Protection afforded by sickle-cell trait against subtertian malarial infection.

314 (18.5) L Schamroth, D M Krikler, and C Garrett. 1972;i:660-2. Immediate effects of intravenous verapamil in cardiac arrhythmias. these were reviewed up to $1985 .^{8}$ But citations have risen again recently - from eight in 1985 and nine in both 1986 and 1987 to 10 in 1988 and 12 in 1989. Many of these references have been in papers written in the aftermath of natural disasters and terrorist incidents. Most recently, the paper was cited in a report on crush injuries after the Armenian earthquake. ${ }^{9}$

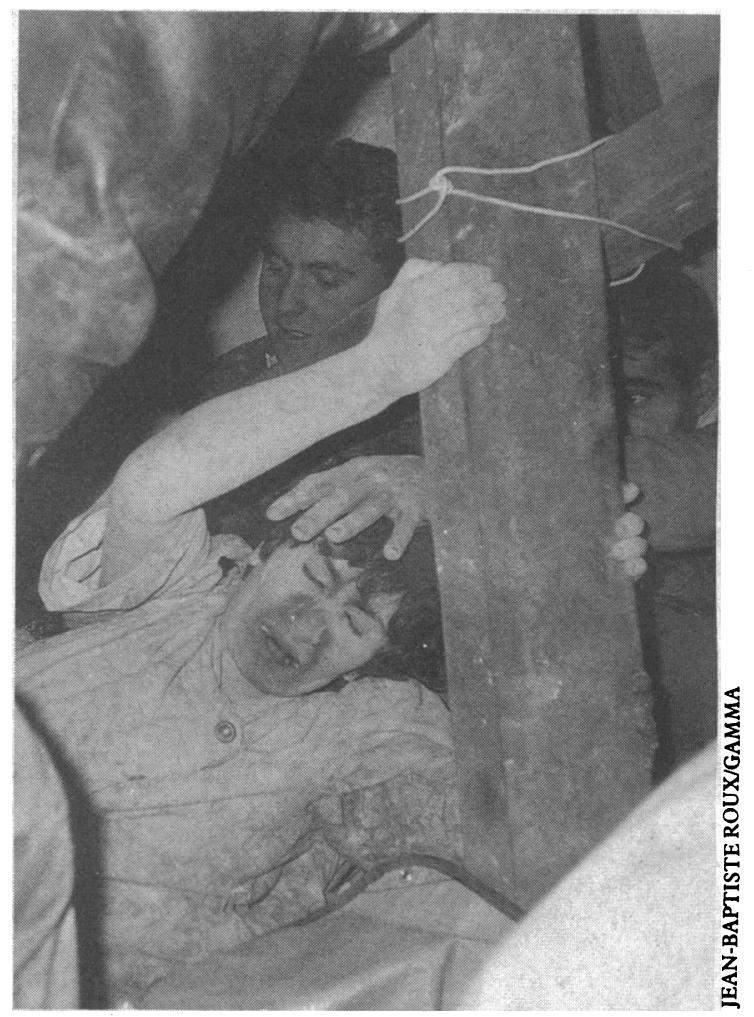

A survivor is rescued 35 days after the Armenian earthquake

Assessed on the basis of performance in the immediate past, the strongest paper in the collection is that in which E K Perry and colleagues first suggested that there was a close relation between the formation of plaques in patients with Alzheimer's disease and choline acetyltransferase activity in the cerebral cortex. This paper's 63,52 , and 72 citations in 1987,1988 , and 1989 , respectively, have brought it up to a total count of 500 since the report appeared in 1978. Not far behind is the Regular Review article by Tim Crow (1980), which focused on genetic influences in schizophrenia and the possibility that a slow virus is involved. With a total count of 375 citations it has attracted 53, 50 , and 44 citations in the past three years.

Sometimes, an explanation other than peer group popularity is possible when a paper continues to be highly cited many years after publication. An excellent example is afforded by the 1973 report in which Danish neurologist Svend Strandgaard and his colleagues showed that the lower limit of blood pressure during autoregulation of cerebral blood flow in patients with chronic hypertension is shifted towards high pressure, impairing tolerance to low blood pressure. Reflecting on this paper 15 years later, Strandgaard suggested that his work went comparatively unnoticed until around 1980, when a wave of clinical papers appeared on cerebral ischaemia caused by overtreatment of severely hypertensive patients ${ }^{10}$; the present number of citations is 299. But he said that there could have been an additional reason for its high citation rating"because I have written a host of reviews on the subject and have quoted the work incessantly." 
313 (6.5) E G L Bywaters and D Beall. 1941;i:427-32. Crush injuries with impairment of renal function.

313 (8.9) D M Davidson and D Robertson Smith. 1954;ii:6-7. A morphological sex difference in the polymorphonuclear neutrophil leucocytes.

312 (9-5) R Doll and A Bradford Hill. 1956;ii: 1071-81. Lung cancer and other causes of death in relation to smoking.

308 (18.1) H Atkins, J L Hayward, D J Klugman, and A B Wayte. 1972;ii:423-9. Treatment of early breast cancer: a report after ten years of a clinical trial.

$308(11.8) \mathrm{A} \mathrm{W}$ Liley. 1963;ii:1107-9. Intrauterine transfusion of foetus in haemolytic disease.

308 (14.7) F E Speizer, R Doll, and P Heaf. 1968;i:335-9. Observations on recent increase in mortality from asthma.

$306(9 \cdot 9)$ E W Walton. 1958;ii:265-70. Giant-cell granuloma of the respiratory tract Wegener's granulomatosis)

$304(15 \cdot 2)$ B Alexanderson, D A P Evans, and F Sjoqvist. 1969;iv:764-8. Steady-state plasma levels of nortriptyline in twins: influence of genetic factors and drug therapy

$300(18.8) \mathrm{T}$ Wheeler and P J Watkins. 1973;iv:584-6. Cardiac denervation in diabetes.

299 (18.7) S Strandgaard, J Olesen, E Skinhoj, and N A Lassen. 1973;i:507-10. Autoregulation of brain circulation in severe arterial hypertension.

298 (14.0) F E Speizer, R Doll, P Heaf, and L B Strang. 1968;i:339-43. Investigations into use of drugs preceding death from asthma.

297 (37-1) L Poston, R B Sewell, S P Wilkinson, P J Richardson, R Williams, E M Clarkson, G A MacGregor, and H E De Wardener. 1981;282:847-9. Evidence for a circulating sodium transport inhibitor in essential hypertension.

$292(8 \cdot 3)$ P Wood. 1954;i: 1051-66. An appreciation of mitral stenosis. Part 1. Clinical features.

$291(14 \cdot 6)$ N Hurwitz. 1969;i:536. Predisposing factors in adverse reactions to drugs.

$288(16.0)$ N S Painter and D P Burkitt. 1971;ii:450-4. Diverticular disease of the colon; a deficiency disease of Western civilization.
I thank Dr Eugene Garfield and David Pendlebury of the Institute for Scientific Information, Philadelphia, for providing the raw data used in this paper; and Dr Chris Langley of the Ciba Foundation, London, for help with library facilities.

1 Shaw JG. Article-by-article citation analysis of medical journals. Scientometrics 1987;12:101-10.

2 Garfield E. Citation indexes for science. Science 1955;122:108-11.

3 Stewart AM. A survey of childhood malignancies. In: Barrett JT, ed. Contemporary classics in clinical medicine. Philadelphia: ISI Press, 1986:123.

4 Besser GM. Galactorrhoea: successful treatment with a reduction of plasma prolactin levels by bromo-ergocryptine. Current Contents/Life Sciences 1988; 37:12.

5 Steering Committee of the Physicians' Health Study Research Group. Final report on the aspirin component of the ongoing physicians' health study. NEngl I Med 1989;321:129-35.

$6 \mathrm{~W}$ right BM. Maximum forced expiratory flow rate as a measure of ventilatory capacity. In: Barrett JT, ed. Contemporary classics in clinical medicine. Philadelphia: ISI Press, 1986:314.

7 Jones KP, Mullee MA. Measuring peak expiratory flow in general practice: comparison of mini Wright peak flow meter and turbine spirometer. $\mathrm{Br} M e d \mathcal{f}$ 1990;300:1629-31

8 Garfield E. The 101 most-cited papers from the British Medical fournal highlight the important role of epidemiology in medicine. Current Contents 1987;7:3-12.

9 Richards NT, Tattersall J, McCann M, Samson A, Mathias T, Johnson A. Dialysis for acute renal failure due to crush injuries after the Armenian earthquake. Br Med f 1989;298:443-5.

10 Strandgaard S. Autoregulation of brain circulation in severe arterial hypertension. Current Contents/Life Sciences 1987;21:21.

\section{Concourse No 2 (1948)}

\section{Barbara Hepworth (1903-75; British)}

Between 1947 and 1949 the sculptress Barbara Hepworth made a series of drawings of orthopaedic operations, largely from memory but based on notes that she was allowed to make on a sterile pad in the operating theatre. Shunning the dramatic possibilities of the operating theatre as a setting, Hepworth produced austere drawings of immense power. In format "Concourse No 2" is reminiscent of a classical frieze, in which the figures have all the monumentality of sculpture. Our attention is drawn to the eyes and hands, perhaps an unconscious reference to Dürer's "Christ Among the Doctors" but without his sinister intent. The atmosphere is one of peace and calm and owes much to the technique she used: a combination of oil and pencil, the green wash blending the gowns with the background.

Hepworth's friendship with the orthopaedic surgeon Norman Capener, who had operated on her daughter, enabled her to make these drawings, both in his unit at Exeter and at the Royal National Orthopaedic Hospital in London.

\section{CLASSIC OF THE DECADE}

1942: William Henry Beveridge's Report on Social Insurance and Allied Services. London: HMSO.

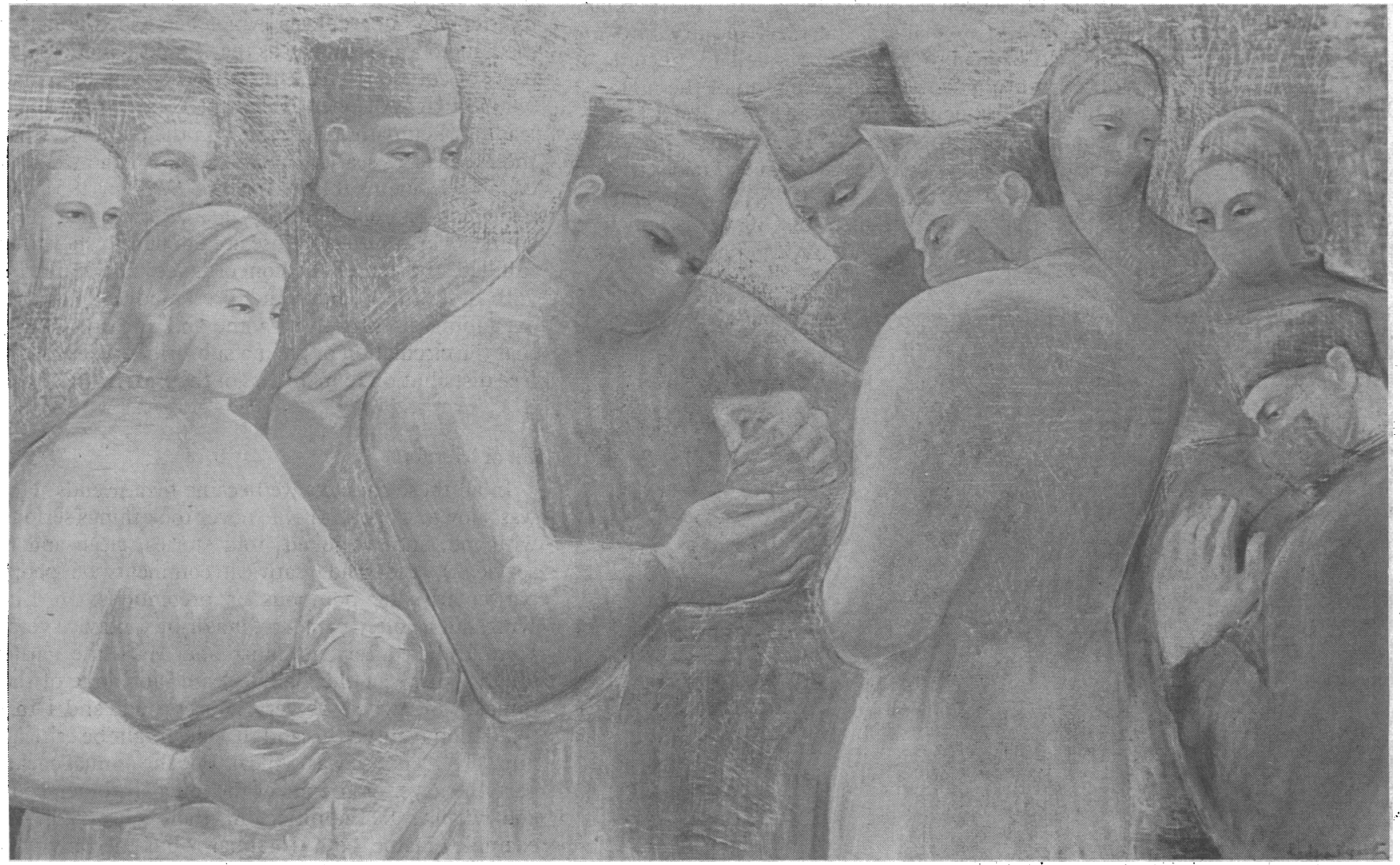

